\title{
The Way Forward with Historic Urban Landscape Approach Towards Sustainable Urban Development
}

\author{
Yonca Erkan \\ Faculty of Art and Design, Kadir Has University, Istanbul, Turkey \\ Email: yonca.erkan@khas.edu.tr
}

\begin{abstract}
The pace of urbanisation, with the increase in the number of metropolitan areas, has been paralleled with the heritage discourse of past generations that valorises monuments in isolation, and has pushed the appreciation of urban heritage to a grim corner in the face of development. Since the turn of the millennium there are international efforts to reverse this trend by placing culture and people-centred approaches into the heritage discourse in order to allow inclusive policies that see culture and cultural heritage as an asset and driving force for sustainable urban development. As one of such instruments, the UNESCO Recommendation on the Historic Urban Landscape, as an integrated management model, is considered in this article to have potentials to bridge existing divides to achieve sustainable urban development. With this belief, the paper looks into the future, with supporting arguments that come from discussions as a result of the WHITRAP International Expert Meeting on the Implementation of the HUL approach which took place in 2018, Shanghai, China.
\end{abstract}

KEYWORDS Historic Urban Landscape approach, civic engagement, urban heritage, people-centred, culture, sustainable development

Received October 30, 2018; accepted December 23, 2018.

Latest trends in human development have put increasing pressures on cities for their progressive development. Local authorities are competing with one another to create and boost competitive, dreamlike world cities that are economically thriving. Citizens, on the other hand, are in search for liveable places where they can enjoy and develop culturally in healthy environments while they are economically functional. Furthermore, challenges such as global warming, social inequalities, and conflicts have added to these complexities, resulting in widespread migrations putting pressure both on the cities as well as to the rural areas. In dealing with these issues, existing urban management systems and mechanisms illustrate insufficiencies in acknowledging the potentials that lie in cultural resources. Since the turn of the millennium, the established policy instruments available to the mainstream heritage discourse that developed after 1960s have been opened to criticism. Discussions led to new conventions, such as UNESCO Convention for the Safeguarding of Intangible Cultural Heritage (2003) and UNESCO Convention on the Diversity of Cultural Expressions (2005), to embrace concepts such as heritage community, common heritage and participation into the debate. Kisic identifies this shift moving away from the mainstream heritage discourse to inclusive heritage discourse (Kisic 2016). This considers the potential of culture not as a burden to the city, but as a positive contribution to the quality of life, development of the society and in reducing the negative impacts of global pressures and heritage dissonance.

Experts time and again try to explain and demonstrate these benefits, yet the research proves that, when cultural resources are not assumed a function that are economically viable, societies will have a harder time appreciating values and cultural practices in their lives (Corten et al. 2014). This disparity is born as a consequence of the policies that utilised autonomous management mechanisms for addressing complex issues instead of holistic approaches that are integrated. Especially through modernity, divides between scientific disciplines/departments/ ministries/societies/countries became wider. This ultimately has led development priorities to take over needs of people and their cultural growth and focus more on 
capital making. Kisic believes that present day conflicts are embedded in contested interpretations of the past which can be overcome by proper governance of cultural heritage (Kisic 2016).

Pioneers of urban planning such as Patrick Geddes (1854-1932) acknowledged this problem long ago in suggesting an integrated urban management approach; unfortunately, his impact was limited in the face of pressing modernity (Rodwell 2018). Starting in the 1970s the importance and need for holistic approaches especially for urban areas grew (González Martínez 2017). At the turn of the millennium, the challenges faced globally pushed UNESCO to take a more active role-as the prime UN agency for culture-in promoting culture for sustainable development. In addressing urban areas, the UNESCO Recommendation on the Historic Urban Landscape (HUL Recommendation) accepted in 2011 was the first instrument developed after 35 years to manage problems arising from rapid urban development, and proposed an integrated approach that would place development and conservation of urban heritage on the same plane (UNESCO 2011) ${ }^{1}$. Meanwhile, the landscape concept and its appreciation became widely accepted through other international instruments such as the European Landscape Convention. The Convention described landscape as a 'basic component of the European natural and cultural heritage ... in urban areas and in the countryside ... in areas recognised as being of outstanding beauty as well as everyday areas', and promoted the protection, management, and planning of the landscape 'as an essential component of peoples' surroundings, an expression of the diversity of their ... heritage, and a foundation of their identity' (Ripp and Rodwell 2015). This new discourse made possible, and at the same time, became a response to, existing divides between the conservation of cultural heritage and urban planning. In the following years, the UN 2030 Sustainable Development Agenda in its Target 11.4 highlighted the importance of safeguarding natural and cultural heritage for safe, inclusive and resilient cities.

The HUL Recommendation, although not a binding document, reflects shared aspiration of UNESCO Member States to take action and address current challenges that cities are facing. The Recommendation is applicable to all urban areas with different sizes and contexts, and is not attached to the World Heritage Convention. The integrated approach as it is promoted in the Recommendation provides tools for making urban heritage a resource for urban development. Although its application is beyond the properties on the World Heritage List, it is equally applicable to urban areas that are in and around World Heritage properties (Bandarin and van Oers 2014).

Furthermore, the HUL Recommendation aims to bridge another divide, commonly observed in different parts of the world, which is the link between people in the form of various stakeholders, local communities and decisionmaking capacities for cultural heritage. The HUL Recommendation promotes civic engagement tools to empower people in the decision making processes. By doing so, it aims to ensure that cultural heritage values are negotiated and agreed at all levels of implementation. This would increase the level of embracement and adoption, enhancing identities of the societies which would ensure the longevity of the cultural resources. Active participation would also allow the growing dynamic nature of the development of societies while improvement of a wide variety of stakeholders could enrich the identification of values beyond the historic core extending to the broader urban context, and include multiple layers. The Historic Urban Landscape is defined in the HUL Recommendation as follows:

the urban area understood as the result of a historic layering of cultural and natural values and attributes, extending beyond the notion of 'historic centre' or 'ensemble' to include the broader urban context and its geographical setting. This wider context includes notably the site's topography, geomorphology, hydrology and natural features, its built environment, both historic and contemporary, its infrastructures above and below ground, its open spaces and gardens, its land use patterns and spatial organisation, perceptions and visual relationships, as well as all other elements of the urban structure. It also includes social and cultural practices and values, economic processes and the intangible dimensions of heritage as related to diversity and identity. This definition provides the basis for a comprehensive and integrated approach for the identification, assessment, conservation and management of historic urban landscapes within an overall sustainable development framework (UNESCO 2011).

Looking at the urban area beyond the historic core entails redefining the boundaries of the city and signals the necessity for developing a new urban taxonomy which may also include small settlements and informal settlements. In the international community, as there is no agreed definition of the 'city', rethinking its meaning might be fruitful as our understanding of city changes as our needs expand. The integrated approach and its principles as it is promoted in the HUL Recommendation provide opportunities to 
address many of the challenges that are identified by the international community targeting urban areas. Article 11 of the HUL Recommendation claims that it is

aimed at preserving the quality of the human environment, enhancing the productive and sustainable use of urban spaces, while recognising their dynamic character, and promoting social and functional diversity. It integrates the goals of urban heritage conservation and those of social and economic development. It is rooted in a balanced and sustainable relationship between the urban and natural environment, between the needs of present and future generations and the legacy from the past (UNESCO 2011).

The variety of possible areas of use for the HUL approach ranges from reconstructions and recovery processes for cities or urban areas following conflicts and disasters to self-generated urban regeneration schemes. Due to the fact that the principles in the HUL Recommendation are fully compatible with other UNESCO conventions and UN documents, especially the UN 2030 Agenda, it is a means of implementation at the local level. The HUL approach ${ }^{2}$ can be used at various stages of urban initiatives as it is suggested by the joint Position Paper prepared by the World Bank and UNESCO on Culture in City Reconstruction and Recovery (UNESCO and World Bank 2018).

Due to the intergovernmental nature of the Recommendation, it requires a strong commitment of decision-makers to make use of this approach in their national contexts. Following the 2030 Agenda for Sustainable Development, the New Urban Agenda brought up by UN-Habitat, sets specific agendas for urban citizens for planning the coming decades. However, it does not provide established methodology on how this is achieved but highlights that there is a need for an integrated territorial development which can be addressed through the HUL approach. An integrated urban management approach that embraces development, as well as potentials of culture, is a strong tool for adapting the New Urban Agenda to national urban policies that are compatible with the 2030 Agenda.

In the presence of robust commitment of the international community set out in the unanimously agreed international mechanisms such as the 2030 Agenda and the New Urban Agenda, it would be a second missed opportunity after the case of Geddes to leave out integrated urban management approaches from current practices that allow an inclusive heritage discourse. The potential existing in the HUL Recommendation should be harnessed to the
HISTORIC [Layers: old and new] URBAN [Heritage: tangible and intangible]

\section{LANDSCAPE [setting: nature and culture] APPR $\mathrm{A} C \mathrm{H}$ [Management: community involvement and partnerships]

Figure 1 HUL approach and its attributes (Source: the author).

greatest possible extent, integrating urban planning with the conservation of urban heritage through empowering people, while at the same time promoting creativity and cultural expressions, that are the essentials of a healthy society. Currently, the world is faced with critical decisions in addressing climate change, conflicts and inequalities that are more severely felt in cities. In addressing these challenges, the tools available in the HUL approach and their benefits for the urban environment will be presented in the coming paragraphs.

At this point and forward-looking to the future, we need to increase the number of good practices in urban governance. In planning the long-term visions, the first priority should be given to people, keeping in mind that the notion of sustainable development is for people and it can only be achieved by the commitment of people. Cultural heritage is the supreme contribution of humanity which carries in itself the wisdom, knowledge and vehicle of long-term visions and ideas for the future. Therefore, culture is an essential component of sustainable development.

\section{The HUL Approach}

The HUL approach can be considered as the new generation of urban planning, integrating territorial values with local ones; historic layers with the present day environment, linking culture and nature; and intangible values with current global practices (Figure 1).

The most significant aspect is that it addresses different urban scales (from metropolis to small settlements) and typologies (from walled cities to modern cities) as well as playing an integrative role between different networks of stakeholders. These goals can be achieved by applying the four tools through an action plan that is circular in nature (Figure 2) ${ }^{3}$. The circular nature of this scheme allows cities with different needs to jump start using the Historic Urban Landscape approach at any moment. 


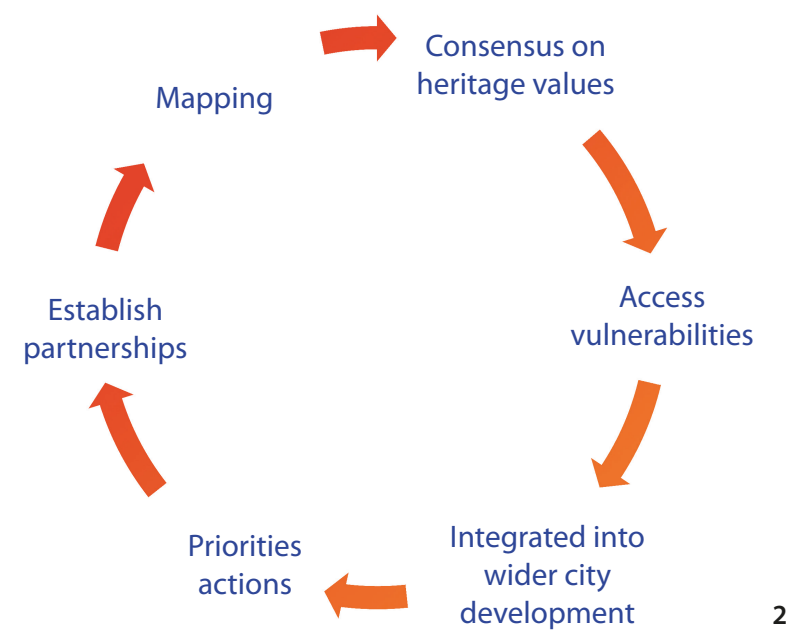

Figure 2 Action Plan for HUL approach (Source: the author).

\section{Regulatory Mechanisms}

The UN-Habitat New Urban Agenda places great emphasis on the enhancement of urban governance. The mechanisms of urban governance may vary from one place to the other, yet it should ideally facilitate the negotiation of diverse interests. With a long-term vision, through strategic planning, current situation and vulnerabilities should be analysed, existing resources should be defined, and actions should be prioritised. The areas of responsibilities should be clearly delineated and overlapping legislation and control mechanisms be identified. Monitoring mechanisms should be developed alongside the governance tools while recognising the regulatory role this approach can play and how it can be placed within existing national mechanisms. In many cases, national policies are not updated frequently enough to allow them to match the pace of changing global needs demanding dynamic methodologies for prioritisation and decision-making processes.

The HUL approach has the flexibility to adapt to changing forces of urbanism and speaks to both the national and the international agendas, thus it could be entrusted with the responsibility of supporting national urban policies in alignment with the New Urban Agenda. Applying the HUL approach improves and transforms the actual management conditions at any stage of urban development, albeit this may require the engagement of different tools in each case.

Regulatory tools of the HUL approach tend to be harnessed addressing certain threats in the cities, especially in relation to Heritage Impact Assessments, and this works as a reactive mechanism. However, broader benefits can be seen when tools such as impact assessments are applied as a proactive mechanism as in the Strategic/Environmental Impact Assessments.
While the HUL approach addresses urban areas beyond the World Heritage properties, it is equally useful in the nomination process, as part of the preparation of management plans, monitoring properties for their State of Conservation, and in planning actions on the removal of sites from the List of World Heritage in Danger. The focus on the Outstanding Universal Value of the World Heritage properties may be perceived as contradictory to the notion of multiple layers in the Historic Urban Landscape approach, where World Heritage nominations are becoming more and more theme based, therefore focused on a specific period or style. On the contrary, the HUL approach offers an opportunity for reviewing the issue more broadly. This limitation is easily addressed through management plans or mechanisms where the boundaries can exceed the limits of the World Heritage Property. Through implementation of the HUL approach, the management of historic urban areas improves, and recovery and reconstruction processes may take into consideration the culture and cultural heritage, and the empowerment of people. Traditional knowledge that is available in related communities will help in the efforts to reduce the impacts of climate change and enhance social inclusion, ultimately contributing to the international development frameworks.

\section{Civic Engagement Tools}

When we talk about civic engagement tools, we often think of conditions that lead to the questioning of phenomenon like social equality, safe and resilient societies, migrants and their role in the city. Furthermore, recognition of communities including religious and cultural groups as stakeholders is often neglected which may contribute to an increase of tensions in the city that may eventually lead to conflict. Some parts of society such as women/youth/disadvantaged groups may not find opportunities to fully engage in decision-making processes. All of these may alter the distribution of power from the balanced state of a healthy society to an unbalanced situation that favours certain groups/sectors, reducing the essential role of public good in civic life. Capacity building activities for all, intergenerational approach to culture and mapping of all stakeholders and cultural practices, and community-based design are all instruments that enhance civic engagement. The guiding principles, on the other hand, should be to include all levels of society in decision-making processes, ensuring transparency and dialogue towards creating a shared vision. It will then allow consensus for action, opportunities for inclusiveness and dialogue, and for enhancing capacities and diversity of 
the societies contributing to peace and human dignity. Increasing and enhancing civic engagement is a strong instrument in addressing conflict areas and post-disaster situations and their recovery processes.

However, the level of engagement is equally important and a defining factor for successful outcomes with new opportunities available in the form of digital technologies and open platforms. The level of public participation for people-centred solutions may vary from informing to empowerment and where partnerships are an essential component in this process.

\section{Knowledge and Planning Tools}

Research shows that participation is ensured by motivation, opportunities and ability, and they are key factors for successful civic engagement (Rasoolimanesh et al. 2017). Ability is the level of awareness and knowledge of people being the basis for any urban planning and conservation activity. Here, available tools that can enhance the knowledge and awareness of societies are vast and developing every day with the new technologies. The article by Wang on the cultural mapping of Xian Walled City using digital technologies in this issue of Built Heritage is exemplary. The conventional understanding of mapping the built heritage and natural resources along with other aspects of urban development were acknowledged. However, it is equally important to map the informalities in the city, the intangible aspects, scents and sounds which also prove to be significant elements of the genius loci. One of the key distinguishing characteristics of the HUL approach is its stressing diversity and multiplicity of historical layers (old and new), heritage values (natural, cultural-tangible and intangible), and its emphasis on civic engagement beyond the historic core. It is therefore quintessential to look for values deeper than those that are on the surface, and in wider associations. Traditional knowledge and management systems that are on the verge of being forgotten, yet form the fundamentals of urban form and planning, await further attention complementary to present day planning practices.

\section{Financial Tools}

In the introductory paragraphs of this article, it was noted that local authorities are competing with one another to create and boost competitive, dreamlike world cities that are thriving and for sustainable urban development resources when they have not assumed a function that is economically viable. Financial tools, therefore, should aim to bridge this gap and should ultimately assist in generating the capacities for societies to create decent jobs. The research shows that conservation led activities often generate more and long-term employment. Establishing governmental and global funds, fostering private investment, designing flexible financing (micro-credit) models and encouraging local entrepreneurship are useful tools. In doing so, it is beneficial to base income generating actions to be rooted in tradition, employing a variety of models of partnerships beyond public-public, publicprivate models, ensuring that the financial models are sustainable.

The implementation of the HUL approach, when guaranteed by the commitment of government, allows two possible trajectories:

- Update/preparation of national urban policies at the national level

- Update/preparation of management plan/mechanism for a city/urban area at the local level

UN-Habitat contributes to national urban policies through its country assessments providing advice on the setting up of national processes and stakeholder participation; documentation of good practices; analysis of urban planning policies and instruments; facilitation of local-national dialogue on reforms; dissemination and capacity development on the urban policy across the full range of actors. Already, UN-Habitat has supported several urban policy development processes including those of Burundi, Malawi, Mongolia and Sri Lanka (UN-Habitat 2018). Zanzibar is currently collaborating with UN-Habitat on developing their national urban agenda through the HUL approach.

UN-Habitat defines the expected outcomes of the development of a national urban policy as follows:

- The identification of urban development priorities towards socially and economically equitable and environmentally friendly urban and national development;

- Guidance on the future development of the national urban system and its spatial configuration concretised through national and regional spatial plans for territorial development;

- Better coordination and guidance of actions by national actors, as well as lower levels of government in all sectors;

- Increased and more coordinated private and public investments in urban development and consequent improvement of cities' productivity, inclusiveness and environmental conditions (UN-Habitat 2018).

Based on the 2016 New Urban Agenda, the $9^{\text {th }}$ World Urban Forum (Malaysia 2018) organised by UN-Habitat put forward the Kuala Lumpur Declaration on Cities 


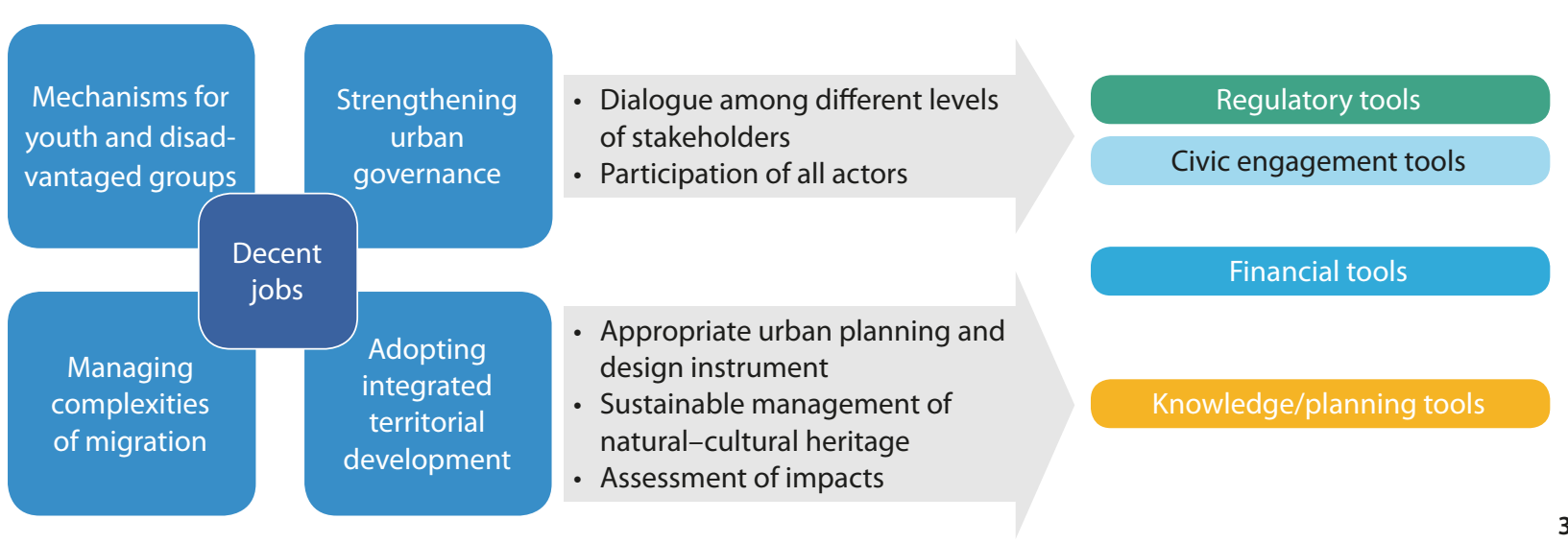

Figure 3 Links between Kuala Lumpur Declaration on Cities and HUL tools (Source: the author).

presenting five global targets to focus in the coming years (Figure 1). Both documents identify problem areas and illustrate ways that they may be overcome. The methodology of the HUL approach and its tools while addressing the same problem areas go beyond this and provide a framework including a set of tools and an action plan that is flexible enough to be applied in cities of different natures scales allowing an integrated management system that harnesses cultural resources to the greatest possible extent (Figure 3). Taking urban heritage as a resource and breathing innovation into urban areas give cities a meaning, supporting culture as an enabler for sustainable development, make cities inclusive, safe, resilient and sustainable. As such, the HUL approach is complementary to the New Urban Agenda, and may be used for its implementation.

\section{The WHITRAP International Expert Meeting on the Implementation of the HUL Approach (26-28 March 2018, Shanghai, China)}

The expert meeting took place at WHITRAP-Shanghai between 26 and 28 March 2018 provided an opportunity to rethink the future of our cities in relation to historic urban areas. The principle aim of the expert meeting was to open certain key concepts of the HUL approach for discussion that could be harnessed as guiding principles especially in the Asia and the Pacific region. Consequently topics such as metropolis, modern heritage, linkages between nature and culture, intangible heritage and digital technologies were given prominence believing that these possible research fields that have rooted traditions in the region would carry forward cities into the future. With culture as the starting point, the HUL approach is promoted as a common denominator through diverse angles as they are presented here in dealing with challenges that the cities are facing currently. As part of UNESCO's wider peoplecentred policy, the HUL approach prioritises the civic engagement at all levels of interventions. The significance of this methodology, in alignment with an inclusive heritage discourse, allows renegotiation of heritage values that are constantly changing. Denison highlights the Western approach to architectural history of modernism and heritage studies that led to heritage dissonance, by way of ignoring the Asian and the African context, underlining the Eurocentrism of the World Heritage List. Denison strongly believes that acknowledgement or narration of other histories is necessary, but also, the current understanding our own histories with a lack of comparison and failure to recognise inter-connectedness should be resolved.

As represented by Huybrechts and Denison, metropolis and the modern heritage emerge as manifestations of our era, our contribution to human history. Huybrechts skilfully defined the attributes of the metropolis and provided a fresh look to the urbanisation phenomenon of our age, diverting our understanding from a victimised condition to a dignified contribution. HUL approach then, becomes operational with its primary motto on seeing the historic urban areas beyond the historic centres in their broader contexts. Several elements are identified by Huybrechts that characterise the metropolis and which could be attributed with heritage values; landmarks as exceptional monuments, water bodies, intangible landscapes and metropolitan artefacts such as congress centres, central business districts, international airports, large ports, exhibition centres, large museums, operas, large 
commercial centres, large universities, and very large hospitals. In conclusion, Huybrechts believes that the HUL approach should be extended to the metropolitan context as it proposes a holistic approach while considering its significance and that the metropolitan heritage could be a recognition of the efforts of local and national government in enhancing the quality of life.

Speaking about the broader context, through the expert meeting it became clear that the intangible aspects play an important role in the Asia and the Pacific urban life, as the region is extremely rich in diverse traditions that have existed for centuries and that can be used as a resource and inspiration for current and future generations. The rural areas are still considered to be resources that can be engaged in the process of sustainability and where Asia and the Pacific have rich rural heritage. The intangible values, are not only engrained in crafts and festivals but also in traditional building technologies and in attitudes towards mitigating risks of disasters and reducing impacts of climate change. Deacon in her article dwelled more on enhancing our understanding of intangible values and heritage in the urban context on a theoretical basis. Emphasising the importance of the Sustainable Development Goals and the HUL Recommendation for dynamic living cities, Deacon suggests that a clearer conceptual understanding of intangible heritage is necessary to effectively integrate it into urban management strategies under the HUL approach. Deacon draws our attention to a risk, noting that intangible heritage becomes worthy of attention only through its association with place. The safeguarding of intangible heritage practices might be included in management planning only where they attest to the authenticity of this built fabric. However, a truly integrated approach would focus both on the landscape values and on the local community or communities and their practices.

The importance of the landscape planning principles in the HUL approach and which valorises the natural components are essential for the social wellbeing in current cities. Ishizawa, expanding on this aspect, demonstrates that the unity of nature-culture, is engrained in Asian conceptualisation and the discussion of a divide between nature and culture is a phenomenon that is a western construct. The notion of the Japanese cultural landscape as a link to nature, albeit under different conceptualisations, is embodied in the satoyama (neighbouring forest) and $s a$ toumi (neighbouring sea), where Shinto beliefs and traditional agricultural practices knit together nature and culture rendering the divide inadequate. As such, it presents a good practise for other regions to consider. Ishizawa looks at the main attributes that function as carriers of the values where nature and culture cannot be separated: the roofs, the terraces, the ritual and the pilgrimage routes and sacred sites. In order to integrate the idea of linking nature and culture and trying to overcome the culturenature divide in the field of heritage, Ishizawa adopts the HUL approach where cultural and spiritual practices feed biodiversity and biodiversity feeds cultural and spiritual practices. This aspect also resonates with the Chinese understanding of seeking harmony between human-nature, human-human and man-mind.

The rapid development and clash of western and Asian customs of looking at their environment necessitates our attention on how to manage the challenges that are transforming the urban environment. Impacts assessments are a strong tool, as highlighted by Turner and Rodwell but they claim that while Heritage Impact Assessment may be relevant to the era of monuments and sites, it is not a suitable tool for addressing today's agendas that are encompassed within cities and urban heritage. The intervention options that are facing our cities demand different tools for evaluation. While Impact Assessment is a reactive tool, there is an urgent need to generate mechanisms that may integrate heritage values within the proactive realm of urban planning and design. They believe that the role of the HUL Recommendation cannot be underestimated in becoming a proactive tool for this purpose ensuring that urban heritage, including its tangible and intangible components, constitutes a key resource in enhancing the liveability of urban areas, and fosters economic development and social cohesion in a changing global environment.

\section{Conclusion}

The Historic Urban Landscape approach acknowledges that human settlements display a variety of urban typologies and scales, yet offers a flexible methodology to address diverse problems in part by encouraging synergies and interactions among urban areas of all sizes and their peri-urban and rural surroundings. Considering that half of the world's population still live in rural areas in traditional settlements with rich cultural resources, these places are of significant importance, being irreplaceable resources for a sustainable future. On the other hand, the current treatment of the boundaries of historic areas and as frontiers delineating areas of no development is too rigid. However Historic Urban Landscape approach suggests that the boundaries may be understood as a set of regulatory systems changing gradually from the core to the periphery. This would possibly allow reconsideration of the boundaries, layered with 
composite values and new meanings beyond the historic cores allowing a more fluid and continuous urban growth. The HUL approach considers urban areas beyond the historic centres in their broader contexts, as testified by the cases of Bordeaux, Naples and Strasbourg. It empowers culture-led activities and thus contributes to the livelihood of the citizens and enhances the quality of urban space for people, such as in Ballarat. Furthermore, intangible aspects play an important role for the HUL approach, as very well demonstrated in Asia and the Pacific urban life sensitising the role of communities and thus enhancing social inclusion. However, in many countries, the practice of urban planning is in crisis. The void in theory, filled by private market incentives, does not necessarily prioritise people's needs. In such cases, Impact Assessments are useful in the HUL framework, as they allow a more proactive planning mechanism, focusing on the sustainable use of our resources, cultural, human and financial.

The way to successful implementation of the HUL approach comes from its ability to connect with international agendas, the commitment of governments to localise these international agendas at the national level through integrated urban management mechanisms and successful models to empower public engagement with the establishment of various partnerships. Finally, the transformative power of the HUL approach needs to be communicated by sharing good practices with wider communities through professional and civic networks. The relevant examples need to be expanded to multiply the transformative power of this integrated approach of urban management to respond to challenges and changes of our age. The global HUL reporting process for the UNESCO General Conference in 2019 is an important step towards developing the Resource Manual on the Historic Urban Landscape approach. In order to achieve this goal, UNESCO should be supported in its efforts to make the HUL approach a tool to promote culture for sustainable urban development.

\section{Notes}

1. The latest international instrument addressing historic towns before UNESCO Recommendation on the Historic Urban Landscape in 2011 was the 1987 ICOMOS Charter for the Conservation of Historic Towns and Urban Areas (Washington Charter).

2. There are two distinct versions for referencing the HUL Recommendation. The first usage referring to the Historic Urban Landscape as an urban area as described in the HUL Recommendation as well as in the Vienna Memorandum. The other version is to illustrate
Historic Urban Landscape as an approach to urban management. The author observes that the first usage is practiced by experts more frequently in identification and conservation, while the second usage is associated with management and planning.

3. The benefits of the circular nature of the Action Plan were highlighted by Patricia O’Donnell during the WHITRAP International Expert Meeting on the Implementation of the HUL approach, 26-28 March 2018, Shanghai, China (O’Donnell 2018).

\section{References}

Bandarin, Francesco and Ron von Oers. 2014. Reconnecting the City: The Historic Urban Landscape and Future of the Urban Heritage. Chichester: Wiley Blackwell.

Corten, Jean Paul, Ellen Geurts, Paul Meurs, and Remco Vermeulen. 2014. Heritage as an Asset for Inner-city Development. Rotterdam: NAI010 Publishers.

González Martínez, Plácido. 2017. “Built Heritage Conservation and Contemporary Urban Development: The Contribution of Architectural Practice to the Challenges of Modernisation." Built Heritage 1 (1): 14-25.

Kisic, Višnja. 2016. Governing Heritage Dissonance. Belgrade: European Cultural Foundation.

O'Donnell, Patricia. 2018. "The Benefits of the Circular Nature of the Action Plan was Highlighted." Paper presenting at the WHITRAP International Expert Meeting on the Implementation of the HUL Approach, Shanghai, March 26-28.

Rasoolimanesh, S. Mostafa, Jaafar Mastura, Ahmad A. Ghafar, and Barghi Rabeeh. 2017. "Community Participation in World Heritage Site Conservation and Tourism Development." Tourism Management 58: 142-153.

Ripp, Matthias and Dennis Rodwell. 2015. "The Governance of Urban Heritage." The Historic Environment: Policy and Practice 6 (3): 240-276.

Rodwell, Dennis. 2018. “The Historic Urban Landscape and the Geography of Urban Heritage." The Historic Environment: Policy and Practice 9 (3): 4, 180-206.

UNESCO. 2011. "UNESCO Recommendation on the Historic Urban Landscape." Accessed 24 December 2018. https://whc.unesco.org/en/hul/

UNESCO and World Bank. 2018. Culture in City Reconstruction and Recovery. Paris: UNESCO and World Bank. https://openknowledge.worldbank.org/ handle/10986/30733

UN-Habitat. 2018. "National Urban Policy." Accessed December 24 2018. https://unhabitat.org/urban-initiatives/initiatives-programmes/national-urban-policies/ 